prospect with regret and see the middle-aged and elderly as very important aspects of their work. The recommended increase of $6 \%$ will do nothing to help solve the ever-increasing work load.

Retford, Notts

E J MORTON

\section{Chromium and diabetes}

SIR,-In regard to the effect of yeast extracts on diabetes discussed recently in the $B M \mathcal{Y}$ (4 December, p 1366, and 2 April, p 905) I would like to add the following comments.

It has indeed been claimed that chromiumdeficient diets result in mild carbohydrate intolerance in the rat. ${ }^{1}$ Recently we have studied chromium-deficient rats with intravenous glucose tolerance tests ${ }^{2}$ using the exact methodology of Mertz et al. ${ }^{1}$ We found only an extremely mild degree of carbohydrate intolerance, which could not even be confirmed by means of analysis of the fractional rate $(\mathrm{K})$

The studies regarding the effect of supplemental dietary chromium on human diabetes are not by any means conclusive. ${ }^{3}{ }^{4}$ However, very recently Jeejeebhoy et $a l^{5}$ have reported on one patient on parenteral nutrition for five years and with negative chromium balance who developed mild carbohydrate intolerance and neuropathy. These changes were corrected by the addition of chromium to her infusate. This is, so far, the most direct evidence that chromium deficiency, probably of a degree much more pronounced than that induced in our experimental model, ${ }^{2}$ can result in mild carbohydrate intolerance. In the light of these considerations the severity of diabetes in the patient described by $\mathrm{Dr}$ Herepath $^{6}$ in 1854 seems hardly compatible with the carbohydrate intolerance of chromium deficiency.

Section of Endocrinology,

Department of Medicine,

Minneapolis, Minnesota

'Mertz, W, Physiological Reviews, 1969, 49, 163.
Woolliscroft, J, and Barbosa, J, fournal of Nutrition. In press.

In press. Streetan, D, and Doisy, J, Metabolism
Levine, R, St 1968, 17, 114

- Sherman, L, Glennon, J, and Brech, W, Metabolism

$1968,17,439$.

- Jeejeebhoy, K, et al, American fournal of Clinical

Nutrition, 1977, 30,531.

Herepath, W B, Yournal of the Provincial Medical and

Surgical Society, 28 April 1854, p 374.

\section{Rubella in early pregnancy}

SIR,-I would like to draw attention to one means of reducing the incidence of the congenital rubella syndrome.

Two children born in December 1975 at two other hospitals in East Anglia have the clinical picture of congenital rubella-that is, microcephaly, mental retardation, heart lesions, failure to thrive, and in one case bilateral cataracts. Antibody levels are consistent with the diagnosis. Both mothers had experienced a mild febrile illness with rash, one at six and the other at nine weeks of pregnancy. One did not seek medical advice; the other did and was not investigated. Each was seen in the norma way at an antenatal clinic a few weeks later, when blood was sent for antenatal rubella examination and reported as showing evidence of immunity.

In neither instance was the mother asked about the occurrence of illness or a rash during the preceding weeks of the pregnancy. Had a history of a rash been obtained the diagnosis of recent rubella infection may well have been supported by serological tests and a termination of pregnancy considered.

Should not all physicians and antenatal clinics introduce the question "Have you had a rash since your last period?" into their questionnaire for "booking in" patients and if the answer is affirmative get the laboratory to help? A history of "German measles as a child" is known to be misleading' and immunity assumed from any other unsubstantiated evidence would be best disregarded in favour of a proper serological examination.

Public Health Laboratory,

J NAGINGTON

Addenbrooke's Hospital,

Cambridge

Public Health Laboratory Service Working Party on Rubella, British Medical fournal, 1968, 3, 203.

\section{Infantile acne}

SIR,-Both my children within the first few weeks of life developed what, for want of a better description, is termed infantile acne. This was, as you can imagine, disturbing for the loving parents and led to considerable searching through dermatological texts. In common with many other skin disorders there appeared to be no effective treatment. The most popular explanation to explain the skin lesions was withdrawal of maternal oestrogen and progesterone at birth.

Both children were breast-fed and, to the delight of mother and father, the unsightly spots rapidly disappeared when the former resumed taking a low-dose oral contraceptive preparation. I have recently witnessed the same phenomenon with a neighbour's child.

This uncontrolled observation may lend weight to the "withdrawal of maternal hormone" theory. I wonder whether any of your other readers have had a similar experience.

D ROWLEY-JONES

Baldock, Herts

\section{Treatment of mild hypertension}

SIR,-In the preamble to the report of the MRC Working Party on Mild to Moderate Hypertension (4 June, $p$ 1437) it is pointed out that the argument for considering treatment of mild hypertension depends on the beneficial results claimed in the treatment of severe hypertension, and in particular on the report of the Veterans Administration study of $1967 .^{1}$ If the working party is satisfied with that, as it appears to be, it follows that there should already be enough data available from its pilot study to render the $£ 2 \mathrm{~m}$ full-scale study superfluous. The VA study was based on 143 cases studied for just over two years. The MRC trial included 1849 persons, some studied for over three years. For some reason the incidence of cardiovascular episodes in this group was not disclosed.

The Framingham study ("the best available"2) indicates that in the age group studied one would expect about a $4 \%$ annual incidence of cardiovascular episodes. The MRC pilot study should therefore contain about 100 events of this sort, even allowing for any reduced incidence from the treatment.
According to Peto et $a l^{3} 100$ events should permit an even chance of detecting a $50 \%$ benefit from treatment. Admittedly this is not as high as the $95 \%$ chance aimed at in the MRC trial (in my view unnecessarily high). However, if I were funding the MRC (which in a way I am) I would not be inclined to endorse a full-scale trial without information on the results of the pilot trial. It would be a colossal undertaking and likely to be of very dubious benefit according to the Harvard workers. ${ }^{1}$

HaRry HaLl

Exeter

' Veterans Administration Co-operative Study Group, Journal of the American Medical Association, 1967, Fournal of 1028 .

${ }^{2}$ Stason, C, and Weinstein, M C, New England fournal

of Medicine, 1977, 296, 732.
${ }^{3}$ Peto, $\mathrm{R}$, et al, British fournal of Cancer, 1976, 34, 585.

\section{Cranial arteritis: atypical presentation}

SIR,-Further to the correspondence regarding cranial arteritis (21 May, pp 1348 and 1355; 11 June, $p$ 1534), I feel that an illustration of an atypical presentation might be of interest, partly because the typical clinical picture is usually so marked and also to prove that lightning can strike twice in the same place.

In 1967 a previously fit 78-year-old man presented with pain in the tongue on eating or rapid repeated protrusion of the tongue but not on drinking or repeated jaw movements alone. Biopsy confirmed the diagnosis of arteritis and corticosteroid therapy was started. The tongue pain and malaise had disappeared one week later. ${ }^{1}$ Recently a female patient aged 77 presented with identical symptoms and signs and a raised erythrocyte sedimentation rate. A dramatic improvement was obtained on starting steroid therapy. It is interesting that this obviously uncommon presentation should have occurred twice in one practice and it exemplifies the fact that other arteries than the temporal can be affected.

I feel that note should also be taken of the complaint of general malaise which is commonly associated with the severe headaches described by Dr R V H Jones (21 May, p 1355) and which is rapidly improved once steroid therapy is instituted.

K D LAWREY

Seaton, Devon

\section{Control of blood glucose in labour}

SIR,-We would like to reiterate what was said by $\mathrm{Dr}$ Judith $M$ Steele and her colleagues (11 June, p 1537) about the use of continuous intravenous insulin and glucose administration in the treatment of diabetic labour. Over the past two years we have been using $10 \%$ dextrose with Actrapid insulin and potassium chloride added direct to the dextrose solution. When infused over five hours this provides insulin at $2 \mathrm{U} / \mathrm{h}$, glucose at $10 \mathrm{~g} / \mathrm{h}$, and potassium at $2 \mathrm{mmol} / \mathrm{h}$. This can be administered and monitored easily by nursing staff or with a constant infusion pump such as the IVAC. We have not added albumin or found the use of an insulin syringe necessary. If the insulin dosage needs to be changed another bag of dextrose can be made up with the appropriate amount of insulin added. This usually varies between 1 and $4 \mathrm{U} / \mathrm{h}$. An intravenous infusion bag costs the health 